\title{
PENGARUH STATUS SOSIAL EKONOMI DAN MOTIVASI BELAJAR TERHADAP PRESTASI BELAJAR SISWA KELAS V SDN TAMBAKSARI I SURABAYA
}

\author{
Desi Eka Pratiwi ${ }^{\text {a) }}$, Nindy Eka Prasetya ${ }^{\text {a) }}$ \\ ${ }^{a)}$ Universitas Wijaya Kusuma Surabaya, Surabaya, Indonesia \\ e-mail korespondensi : pratiwidesi27@gmail.com
}

diterima: 29 Januari 2019; direvisi: 15 Februari 2019; disetujui: 26 Februari 2019

\begin{abstract}
This study aimed to determine (1) the effect of socio-economic status on Learning achievement (2) The effect of learning motivation on learning achievement (3) the effect of socio-economic status all together with Learning motivation on learning achievement. The data analysis technique used a simple regression analysis and multiple regression analysis. Furthermore, the prerequisite analysis in the form of Normality test, Linearity test and Multicollinearity test were done before the analysis data was conducted. The results of this study are: (1) There is a positive and significant effect of Socio-Economic Status on Learning Achievement which is indicated by the value of $R$ count $=0.379>R$ table $=0.254$ this variable affects Learning Achievement. (2) There is a positive and significant effect of Learning Motivation on Learning Achievement of Fifth Grade (V) Students of SDN Tambaksari I Surabaya which is indicated by the value of $\mathrm{R}$ count $=0.453>\mathrm{R}$ table $=0.254$ this affects Learning Achievement. (3) There is a positive and significant effect of Socio-Economic Status all toghether with Learning Motivation on Student Achievement of Fifth Grade (V) Students of SDN Tambaksari I Surabaya which is indicated by the value of R count $=0.543>\mathrm{R}$ table $=0.254$ with this jointly influencing Learning Achievement.
\end{abstract}

Keywords: socio-economic status, learning motivation, learning achievement.

\section{PENDAHULUAN}

Pendidikan adalah usaha sadar dan terencana dan sistematis dalam upaya memanusiakan manusia atau belajar pengetahuan, keterampilan dan kebiasaan sekelompok orang diturunkan dari suatu generasi ke generasi berikutnya melalui pengajaran, pelatihan, atau penelitian. Pengertian pendidikan menurut Dewey adalah proses pembentukan kecakapan-kecakapan yang fundamental secara intelektual dan emosional ke arah alam dan sesama manusia. Berbeda dengan pengertian pendidikan menurut Dewantara [1] pendidikan adalah daya upaya untuk memajukan perkembangan budi pekerti (kekuatan batin), pikiran (intelek) dan jasmani anak. Pendidikan adalah usaha sadar dan terencana untuk mewujudkan suasana belajar dan proses belajar agar peserta didik secara aktif mengembangkan potensi dirinya untuk memiliki kekuatan spiritual keagamaan, pengendalian diri, kepribadian, kecerdasan, akhlak mulia, serta keterampilan yang di perlukan dirinya, masyarakat, bangsa dan Negara [2].

Sosiologi pendidikan adalah ilmu yang memelajari seluruh aspek pendidikan, baik aspek-aspek lainnya secara mendalam melalui analisis atau pendekatan sosiologi pendidikan. Pengertian di atas dipertegas dengan peryataan Comte mengatakan bahwa sosiologi adalah suatu studi positif tentang hukum-hukum dasar dari berbagai gejala sosial yang dibedakan menjadi sosiologi statis dan sosiologi dinamis. Sosiologi adalah suatu upaya ilmiah untuk mempelajari masyarakat dan perilaku sosial anggotanya dan menjadikan masyarakat yang bersangkutan dalam berbagai kelompok dan kondisi (Komblum). Johnson sosiologi adalah ilmu yang memepelajari kehidupan dan perilaku terutama dalam kaitanya dalam kaitannya dengan suatu sistem sosial dan bagaimana sistem tersebut mempengaruhi orang dan bagaimana orang yang terlibat di dalam mempengaruhi sistem tersebut. Dari pendapat di atas, dapat disimpulkan bahawa sosiologi adalah ilmu yang mempelajari hubungan antara individu dengan individu, individu dengan masyarakat, dan masyarakat dengan masyarakat. Sosiologi adalah ilmu yang membicarakan apa yang sedang terjadi saat ini, khususnya pola-pola hubungan dalam masyarakat serta berusaha mencari pengertian-pengertian umum, rasional, empiris serta bersifat umum

Status sosial ekonomi orang tua berkaitan dengan kedudukan yang dimiliki oleh orang tua yang dipandang dari kondisi ekonomi dan kondisi sosial di masyarakatnya. Anak memiliki kesempatan lebih luas untuk mengembangkan pengetahuan dan beragam kecakapan atas jaminan dan dukungan ekonomi orang tua. Kondisi sosial ekonomi adalah suatu kedudukan yang diatur secara sosial dan menempatkan seseorang pada posisi tertentu dalam masyarakat, pemberian posisi itu disertai pula dengan seperangkat hak dan kewajiban yang harus dimainkan oleh orang yang membawa status [3]. Pendapatan per-kapita adalah pendapatan rata-rata penduduk suatu negara. Pendapatan nasional dipengaruhi oleh Product domestic Bruto (PDB), yang merupakan salah satu indikator penting untuk mengetahui kondisi ekonomi suatu negara dalam suatu periode tertentu, baik atas dasar harga berlaku maupun atas dasar harga konstan. Variabel yang digunakan untuk menghitung pendapatan per-kapita adalah pendapatan nasional dan jumlah penduduk.

Ada empat tingkatan ekonomi menurut Friedman [4] antara lain: (1) Adekuat: menyatakan uang yang dibelanjakan atas dasar suatu permohonan bahwa pembiayaan adalah tanggung jawab kedua orang tua. Keluarga menganggarkan dan mengatur biaya secara 
ralisitis; (2) Marginal: pada tingkat marginal sering terjadi ketidaksepakatan dan perselisihan siapa yang seharusnya mengontrol pendapatan dan pengeluaran; (3) Miskin: keluarga tidak bisa hidup dengan caranya sendiri, pengaturan keuangan yang buruk akan menyebabkan didahulukannya kemewahan. Diatas kebutuhan pokok, manajemen keuangan yang sangat buruk dapat atau tidak membahayakan kesejahteraan anak, tetapi pengeluaran dan kebutuhan keuangan melebihi penghasilan; (4) Sangat Miskin: menejemen keuangan yang sangat jelek, termasuk pengeluaran saja dan berhutang terlalu banyak, serta kurang tersedianya kebutuhan dasar. Dari uraian status sosial ekonomi di atas dapat disimpulkan bahwa pengertian status sosial ekonomi orang tua adalah gambaran tentang keadaan orang tua yang ditinjau dari segi sosial ekonomi, gambar itu seperti tingkat pendidikan, jenis pekerjaan, tingat pendapatan, pemilikan kekayaan, jenis tempat tinggal dan status sosial ekonomi orang tua itu bisa menjadi pembentukan gaya hidup keluarga, pendapatan keluarga yang tinggi akan menunjang kebutuhan hidup. Karena dengan pendapatan orang tua yang tinggi dapat menyediakan kebutuhan anak baik primer maupun sekunder.

Dalam lingkungan masyarakat terdapat lapisan atasan dengan yang rendah, lapisan yang jumlahnya relatif banyak. Biasanya lapisan atasan yang dihargai oleh masyarakat akan tetapi kedudukan yang tinggi itu bersifat kumulatif artinya mereka yang memiliki uang banyak akan mudah sekali mendapatkan tanah, kekuasaan dan mungkin juga kehormatan. Peneliti berfokus pada status sosial ekonomi masyarakat dari ukuran kekayaan. Kekayaan yang dijelaskan di atas maksudnya barang siapa yang memiliki kekayaan paling banyak termasuk dalam lapisan teratas. Macammacam kekayaan yang dimaksud di atas misalnya dapat dilihat dari bentuk rumah, mobil pribadi, cara-caranya mempergunakan pakaian serta bahan pakaian yang dipakai, kebiasaan untuk berbelanja barang-barang mahal dan seterusnya. Setiap individu dalam masyarakat memiliki status sosialnya masing-masing, status sosial sering pula disebut dengan kedudukan atau status seperti anak, istri, suami, ketua RW, ketua RT, Camat, Lurah, Kepala Sekolah, Guru. Dalam teori sosiologi, unsur-unsur dalam pelapisan masyarakat adalah kedudukan (status) dan peranan (role). Status sosial ekonomi yang peneliti ambil dalam penelitian ini menyangkut kekayaan yang ada pada masyarakat terutama pada orang tua siswa.

Motivasi bukan saja penting karena menjadi faktor penyebab belajar, namun juga mempelancar belajar dan hasil belajar [5]. Secara historik, guru selalu mengetahui kapan siswa harus diberi motivasi selama proses belajar, sehinga aktivitas belajar langsung lebih menyenangkan dan arus komunikasi lebih menyenangkan. Menurut Sardiman [6] menyatakan bahwa motivasi dapat juga dikatakan serangkaian usaha untuk menyediakan kondisi-kondisi tertentu, sehinga seseorang mau dan ingin melakukan sesuatu, dan bila dia tidak suka, maka akan berusaha untuk meniadakan atau mengelakkan perasaan tidak suka itu. Motivasi dapat diransang oleh faktor dari luar tetapi motivasi itu adalah tumbuh di dalam diri seseorang. Dalam kegiatan belajar, motivasi dapat dikatakan sebagai keseluruan daya pengerak di dalam diri siswa yang menimbulkan kegiatan belajar. Proses kelangsungan dari kegiatan belajar dan yang memberikan arah pada kegiatan belajar, sehingga tujuan yang dikehendaki oleh subjek belajar itu dapat dicapai keseluruhan, karenapada umumnya ada beberapa motif yang bersama-sama mengerakan siswa untuk belajar.

Prestasi belajar adalah hasil yang dicapai oleh seseorang setelah dia melakukan perubahan belajar, baik di sekolah maupun di luar sekolah. Hasil belajar yang diharapkan biasanya berupa prestasi belajar yang baik atau optimal. Namun dalam pencapaian hasil belajar yang baik masih saja mengalami kesulitan dan prestasi yang didapat belum dapat dicapai secara optimal.

\section{METODE PENELITIAN}

Pendekatan penelitian yang digunakan adalah menggunakan pendekatan kuantitatif yang termasuk dalam jenis penelitian ex-post facto. Penelitian dilaksanakan pada Kelas V SDN Tambaksari I Surabaya.

Teknik pengumpulan data menggunakan dokumentasi dan lembar angket. Dokumentasi merupakan suatu cara mengumpulkan data dengan jalan mengutip dari sumber catatan yang sudah ada [6]. Tujuan dari dokumentasi digunakan untuk melihat rata-rata nilai Ulangan Harian siswa. Lembar angket dapat berupa pertanyaan/pernyataan tertutup atau terbuka, dapat diberikan kepada responden secara langsung atau dikirim melalui pos atau internet [7]. Angket digunakan sebagai pengumpul data primer yaitu Status Sosial Ekonomi dan Motivasi Belajar.

Teknik analisis data digunakan untuk memeperjelas hubungan antar variabel yang terjadi atau menguji hipotesis dalam penelitian, sedangkan data yang diperoleh akan dianalisis secara kuantitatif melalui uji statistic sesuai dengan hipotesis serta asumsi yang melatar belakangi pemakaian uji static tersebut antara lain. (1) Uji Prasyarat Analisis terdiri dari uji normalitas, uji linieritas, dan uji multikolonieritas. (2) Uji Hipotesis terdiri dari analisis regresi sederhana, analisis dan regresi ganda

\section{HASIL DAN PEMBAHASAN}

1. Uji Validitas Alat Ukur Status Sosial Ekonomi

Terdapat 12 item pernyataan dalam angket variabel kecemasan dan hasil uji validitas menggunakan bantuan komputer program Statistical Packages for Social Scinces (SPSS) for Windows Version 20, diperoleh bahwa semua item pernyataan dinyatakan valid karena $\mathrm{R}$ hitung $>\mathrm{R}$ tabel dengan taraf signifikan 0,05 dan $\mathrm{n}=60$ jadi dapat dilihat nilai $\mathrm{R}$ tabelnya adalah 0,254 . Hasil selengkapnya dapat dilihat dalam lampiran. Adapun rincian item yang valid dapat dilihat pada tabel 1 
Tabel 1. Sebaran Item Status Sosial Ekonomi

\begin{tabular}{|l|c|c|}
\hline \multicolumn{1}{|c|}{ Indikator } & Nomor item & Jumlah \\
\hline Tingkat pendidikan & 1,2 & 2 \\
\hline Tingkat penghasilan & $3,4^{*}$ & 2 \\
\hline Tingkat pekerjaan & 5 & 1 \\
\hline $\begin{array}{l}\text { Fasilitas khusus dan barang } \\
\text { berharga yang dimiliki }\end{array}$ & $6,7,8,9,10$ & 5 \\
\hline Jabatan sosial & 11,12 & 2 \\
\hline
\end{tabular}

Keterangan: * nomor item yang gugur

2. Uji Validitas Alat Ukur Status Sosial Ekonomi Motivasi Belajar

Terdapat 40 item pernyataan dalam angket variable motivasi belajar dan hasil uji validitas menggunakan bantuan komputer program Statistical Packages for Social Scinces (SPSS) for Windows Version 20, diperoleh bahwa 34 item valid dan 6 item tidak valid yaitu nomor item 4,11,12,16,29,34 karena $\mathrm{R}$ hitung > $\mathrm{R}$ tabel. Hasil selengkapnya dapat dilihat dalam lampiran. Adapun rincian item yang valid dan tidak valid atau gugur dapat dilihat pada tabel.

Tabel 2. Sebaran Item Motivasi Belajar

\begin{tabular}{|l|c|c|c|}
\hline \multirow{2}{*}{\multicolumn{1}{|c|}{ Indikator }} & \multicolumn{2}{|c|}{ Nomor item } & \multirow{2}{*}{ Total } \\
\cline { 2 - 3 } & Favorabel & Unfavorabel & \\
\hline $\begin{array}{l}\text { Adanya hasrat dan } \\
\text { keinginan berhasil }\end{array}$ & $1,2,3$ & $7,8,9$ & 6 \\
\hline $\begin{array}{l}\text { Adanya dorongan } \\
\text { dan kebutuhan } \\
\text { dalam belajar }\end{array}$ & $4^{*}, 5,6$ & $10,11^{*}, 12^{*}$ & 6 \\
\hline $\begin{array}{l}\text { Adanya dan cita- } \\
\text { cita masa depan }\end{array}$ & $\begin{array}{c}13,14,15,16 \\
*, 17\end{array}$ & $21,22,23,24,25$ & 10 \\
\hline $\begin{array}{l}\text { Adanya } \\
\text { penghargaan dalam } \\
\text { belajar }\end{array}$ & $18,19,20$ & $26,27,28$ & 6 \\
\hline $\begin{array}{l}\text { Adanya kegiatan } \\
\text { yang menarik dalam } \\
\text { belajar }\end{array}$ & $29 *, 30,31$ & $35,36,37$ & 6 \\
\hline $\begin{array}{l}\text { Adanya lingkungan } \\
\text { belajar yang } \\
\text { kondusif }\end{array}$ & $32,33,34^{*}$ & $38,39,40$ & 6 \\
\hline Total & 20 & 20 & 40 \\
\hline
\end{tabular}

Keterangan: * nomor item yang gugur

\section{Uji Reliabilitas Status sosial ekonomi}

Uji reliabilitas dengan menggunakan komputer program Statistical Packages for Social Scinces (SPSS) for Windows Version 20. Yaitu dengan teknik alpha cronbach terhadap masing-masing skala.

Dari hasil uji reliabilitas skala ini, diperoleh koefsien alpha sebesar 0,577 yang menunjukan bahwa alat ini tergolong reliabel karena alpha $>\mathrm{R}$ tabel, dimana $\mathrm{R}$ tabel $=$ 0,254

Tabel 3. Uji Reabilitas Status Sosial Ekonomi Reliability Statistics

\begin{tabular}{|c|r|}
\hline $\begin{array}{c}\text { Cronbach's } \\
\text { Alpha }\end{array}$ & N of Items \\
\hline & 1277 \\
\hline
\end{tabular}

4. Uji Reliabilitas Motivasi Belajar

Dari hasil uji reliabilitas skala ini, diperoleh koefsien alpha sebesar 0,889 yang menunjukan bahwa alat ini tergolong reliabel karena alpha $>\mathrm{R}$ tabel, dimana $\mathrm{R}$ tabel $=$ 0,254

Tabel 4. Uji Reabilitas Motivasi Belajar

\begin{tabular}{|l|r|}
\hline \multicolumn{2}{|c|}{ Reliability Statistics } \\
\begin{tabular}{|c|r|}
\hline $\begin{array}{c}\text { Cronbach's } \\
\text { Alpha }\end{array}$ & N of Items \\
\hline & 489
\end{tabular} \\
\hline
\end{tabular}

Analisis data dipergunakan untuk memeperjelas pengaruh antar variabel yang terjadi atau menguji hipotesis dalam penelitian, sedangkan data yang diperoleh akan analisis secara kuantitatif melalui uji statistic sesuai dengan hipotesis serta asumsi yang melatar belakangi pemakaian uji static tersebut.

Dalam penelitian ini ingin diketahui hubungan antara kedua variabel bebas yaitu Status Sosial Ekonomi dan Motivasi Belajar dengan variabel terikat yaitu Prestasi Belajar. Untuk mengetahui pengaruh antara variabel digunakan komputer program Statistical Packages For Social Scinces (SPSS) 20 for IBM.

\section{Uji Normalitas}

Uji normalitas berguna untuk menentukan data yang telah dikumpulkan berdistribusi normal atau diambil dari populasi normal Hasil uji normalitas sebaran yang dilakukan dengan program SPSS 20 for IBM.

Tabel 5. Uji Normalitas
One-Sample Kolmogorov-Smirnov Test
\begin{tabular}{|ll|r|r|r|}
\hline & & $\begin{array}{r}\text { prestasi_bela } \\
\text { jar }\end{array}$ & $\begin{array}{r}\text { status_sosial } \\
\text { _ekonomi }\end{array}$ & $\begin{array}{c}\text { motivasi_bela } \\
\text { jar }\end{array}$ \\
\hline N & & 60 & 60 & 60 \\
Normal Parameters ${ }^{\text {a.b }}$ & Mean & 83.4500 & 34.3167 & 161.5167 \\
& Std. Deviation & 12.82136 & 4.75320 & 16.39708 \\
Most Extreme Differences & Absolute & .128 & .096 & .146 \\
& Positive & .098 & .093 & .067 \\
Kolmogorov-Smirnov Z & Negative & -.128 & -.096 & -.146 \\
Asymp. Sig. (2-tailed) & & .992 & .746 & 1.127 \\
\hline a. Test distribution is Normal. & .279 & .634 & .157 \\
b. Calculated from data.
\end{tabular}

Dari hasil perhitungan uji normalitas yang dilakukan menggunakan komputer program Statistical Packages for Social Scinces (SPSS) for Windows Version 20, didapatkan nilai Kolmogorov-Smimov Z Asymp. Sig. sebesar 0,634 untuk status sosial ekonomi, 0,157 untuk motivasi belajar, dan 0,279 untuk prestasi belajar. . Menurut kriterianya adalah jika harga Kolmogorov-Smimov Z Asymp. Sig. lebih besar dari taraf signifikansi yang diambil 0,05 (5\%) maka dinyatakan data berdistribusi normal. Dalam penelitian ini terbukti bahwa Kolmogorov-Smimov $Z$ Asymp. Sig. antara variabel bebas dengan variabel terikatnya adalah lebih besar terhadap taraf signifikansinya 0,05. Maka dapat disimpulkan bahwa variabel motivasi belajar dan motivasi belajar dengan kecemasan memiliki data berdistribusi normal. 


\section{Uji Linieritas}

Uji linieritas ini digunakan untuk mengetahui apakah ada hubungan antara variabel bebas dan variabel terikat berbentuk linier atau tidak. Sebelum dilakukannya uji multikolinirtias, terlebih dahulu melakukan uji linieritas antara variabel $\mathrm{X}_{1}$ dan $\mathrm{Y}$, dan uji linieritas variabel $\mathrm{X}_{2}$ dan $\mathrm{Y}$. Dalam penelitian ini uji linierits dilakukan dengan menggunakan komputer program Statistical Packages for Social Scinces (SPSS) for Windows Version 20.

Tabel 6. Uji Linieritas

\section{Model Summary}

\begin{tabular}{|c|c|c|c|c|}
\hline Model & $\mathrm{R}$ & R Square & $\begin{array}{l}\text { Adjusted R } \\
\text { Square }\end{array}$ & $\begin{array}{l}\text { Std. Error of } \\
\text { the Estimate }\end{array}$ \\
\hline 1 & $379^{\mathrm{a}}$ & .144 & .129 & 11.965 \\
\hline
\end{tabular}

a. Predictors: (Constant), status_sosial_ekonomi

Uji linieritas antara variabel bebas (Status Sosial Ekonomi dan Motivasi Belajar) dengan variabel terikatnya (Prestasi belajar) dilihat dari Deviation from linierity, menurut hasil perhitungan didapatkan nilai Deviation from linierity sebesar 0,398 antara status sosial ekonomi dan prestasi belajar dan sebesar 0,434 antara motivasi belajar dan prestasi belajar. Menurut kriterianya adalah jika harga Deviation from linierity lebih besar dari taraf signifikansi yang diambil 0,05 maka dapat dikatakan memiliki hubungan linier. Dari penjelasan tersebut dapat disimpulkan bahwa hasil dari harga Deviation from linierity > 0,05 atau memiliki hubungan linier.

\section{Uji Multikolinieritas}

Dari hasil uji multikolinieritas yang dilakukan dengan bantuan program Statistical Packages for Social Scinces (SPSS) for Windows Version 20, diketahui bahwa tidak terjadi multikolinieritas antara variabel bebas dengan variabel terikat. Dapat dilihat pada tabel dibawah ini:

Tabel 7. Uji Multikolinieritas Coefficients $^{\text {a }}$

\begin{tabular}{|c|c|c|c|c|c|c|c|c|}
\hline \multirow[b]{2}{*}{ Model } & & \multicolumn{2}{|c|}{ Unstandardized Coefficients } & \multirow{2}{*}{$\begin{array}{c}\text { Standardized } \\
\text { Coefficients } \\
\text { Beta }\end{array}$} & \multirow[b]{2}{*}{$t$} & \multirow[b]{2}{*}{ Sig. } & \multicolumn{2}{|c|}{ Collinearity Statistics } \\
\hline & & $B$ & Std. Error & & & & Tolerance & VIF \\
\hline \multirow[t]{3}{*}{1} & (Constant) & 2.259 & 16.355 & & .138 & .891 & & \\
\hline & status_sosial_ekonomi & .937 & .300 & .347 & 3.122 & .003 & .983 & 1.017 \\
\hline & motivasi_belajar & .304 & .087 & .388 & 3.491 & .001 & .983 & 1.017 \\
\hline
\end{tabular}

a. DependentVariable: prestasi_belajar

Tabel di atas dapat diinterprestasikan bahwa dasar pengambilan keputusan dalam Multikolinieritas yaitu dengan melihat nilai VIF (Variance Inflation Factor). Untuk nilai VIF variabel independen status sosial ekonomi (X1) dan motivasi belajar (X2) dengan variabel dependen prestasi belajar (Y) yakni 1,017 lebih kecil dari 10,00. Sehingga dapat disimpulkan tidak terjadi multikolinieritas.

\section{Uji Hipotesis Analisi regresi sederhana}

Uji ini digunakan untuk mengetahui apakah variabel independen $(\mathrm{X})$ berpengaruh secara signifikan terhadap variabel dependen (Y) signifikan berarti berpengaruh yang terjadi dapat berlaku untuk populasi (dapat digenerasikan). Hal ini regresi sederhana antara variabel independen dengan variabel dependen melalui SPSS 20 diperoleh sebagai berikut:

Tabel 8. Analisis Regresi Sederhana Status Sosial Ekonomi

\begin{tabular}{|c|c|c|c|c|c|c|c|}
\hline \multicolumn{8}{|c|}{ ANOVA T } \\
\hline & & & $\begin{array}{l}\text { Sum of } \\
\text { Squares }\end{array}$ & df & Mean Square & $\mathrm{F}$ & Sig. \\
\hline \multirow{5}{*}{$\begin{array}{l}\text { prestasi_belajar }{ }^{*} \\
\text { status__osial_kkonomi }\end{array}$} & \multirow[t]{3}{*}{ Between Groups } & (Combined) & 5055.628 & 20 & 252.781 & 2.123 & .022 \\
\hline & & Linearity & 1537.190 & 1 & 1537.190 & 12.911 & .001 \\
\hline & & Deviation from Linearity & 3518.437 & 19 & 185.181 & 1.555 & 120 \\
\hline & \multicolumn{2}{|l|}{ Within Groups } & 4643.222 & 39 & 119.057 & & \\
\hline & \multicolumn{2}{|l|}{ Total } & 9698.850 & 59 & & & \\
\hline
\end{tabular}

Dari hasi diatas menjelaskan besarnya nilai $\mathrm{R}=0,379$ dan dijelaskan besarnya prosentase pengaruh variabel bebas (X1) status sosial ekonomi terhadap variabel terikat (Y) prestasi belajar yang disebut koefesien determinasi yang merupakan hasil dari penguadratan $\mathrm{R}$, dari output tersebut diperoleh koefesien determinasi (R2) sebesar 0,144 mengandung pengertian bahwa pengaruh variabel bebas(X!) status sosial ekonomi terhadap variabel terikat $(\mathrm{Y})$ prestasi belajar. Uji regresi sederhana X1 $\mathrm{Y}$ didapatkan hasil $\mathrm{R}$ hitung $=0,379>\mathrm{R}$ tabel 0,254 yang berarti ada pengaruh yang positif antara variabel bebas (X1) status sosial ekonomi dan variabel terikat (Y) prestasi belajar.

Tabel 9. Analisis Regresi Sederhana Motivasi Belajar Model Summary

\begin{tabular}{|c|c|c|c|c|}
\hline Model & $\mathrm{R}$ & R Square & $\begin{array}{c}\text { Adjusted R } \\
\text { Square }\end{array}$ & $\begin{array}{l}\text { Std. Error of } \\
\text { the Estimate }\end{array}$ \\
\hline 1 & $\left(453^{\mathrm{a}}\right.$ & .206 & .192 & 11.526 \\
\hline
\end{tabular}

Dari hasil tersebut dapat diperoleh persamaan regresi besarnya nilai $\mathrm{R}$ hitung $=0,453$ dan dijelaskan besarnya prosentase pengaruh variabel bebas (X1) motivasi belajar terhadap variabel terikat (Y) prestasi belajar yang disebut koefesien determinasi yang merupakan hasil dari penguadratan $\mathrm{R}$, dari output tersebut diperoleh koefesien determinasi (R2) sebesar 0,206 mengandung pengertian bahwa pengaruh variable bebas $(\mathrm{X} 1)$ motivasi belajar variabel terikat (Y) prestasi belajar. Uji regresi sederhana X1 $\mathrm{Y}$ didapatkan hasil $\mathrm{R}$ hitung $=0,453>\mathrm{R}$ tabel $=0,254$ yang berarti ada pengaruh yang positif antara variabel bebas (X1) motivasi belajar dan variabel terikat $(\mathrm{Y})$ prestasi belajar.

\section{Uji Hipotesis Analisi regresi Ganda}

Analisis regresi ganda dua prediktor digunakan untuk menguji hipotesis ketiga. Dengan teknik regresi ganda akan diketahui indeks korelasi ganda dari kedua variabel bebas terhadap variabel terikat, koefisien regresi serta sumbangan relatif dan efektif masing-masing variabel bebas terhadap variabel terikat. Uji regresi ganda dalam penelitian ini menggunakan bantuan komputer program Statistical Packages for Social Scinces (SPSS) 20 for IBM. Pada variabel X1 Status Sosial Ekonomi dan X2 Motivasi Belajar secara bersama-sama terhadap Y Prestasi Belajar R hitung = 
0,453 > R tabel 0,254 maka terdapat pengaruh (X1) dan (X2) secara bersama-sama terhadap (Y).

Tabel 10. Analisis Regresi Ganda

Model Summary

\begin{tabular}{|l|r|r|r|r|}
\hline Model & $\mathrm{R}$ & R Square & $\begin{array}{c}\text { Adjusted } \mathrm{R} \\
\text { Square }\end{array}$ & $\begin{array}{c}\text { Std. Error of } \\
\text { the Estimate }\end{array}$ \\
\hline 1 & $.543^{\mathrm{a}}$ & .295 & .270 & 10.953 \\
\hline
\end{tabular}

a. Predictors: (Constant), status_sosial, motivasi_belajar

Dari hasil penelitian diatas disimpulkan bahwa data kelas V SDN Tambaksari I Surabaya menunjukkan adanya pengaruh yang signifikan. Hal ini diperoleh dari perhitungan program SPSS 20 melalui analisis regresi sederhana. Pengaruh status sosial ekonomi dengan prestasi belajar berdasarkan hasil analisis terhadap pengujian hipotesis diperoleh pengaruh yang signifikan antara status sosial ekonomi terhadap prestasi belajar siswa kelas V SDN Tambaksari I Surabaya yang ditunjukan dengan nilai $\mathrm{R}$ hitung > R table $(0,379>0,524)$.

Pengaruh motivasi belajar dengan prestasi belajar berdasarkan hasil analisis diperoleh $\mathrm{R}$ hitung $>\mathrm{R}$ tabel $(0.453>0,254)$ ang berarti ada pengaruh yang positif antara variabel (X2) motivasi belajar dan variabel (Y) prestasi belajar.

Pada analisis regresi ganda diperoleh pengaruh secara bersam-sama antara status sosial ekonomi dan motivasi belajar terhadap kenakalan remaja menyatakan bahwa terdapat pengaruh positif status sosial ekonomi dan motivasi belajar secara bersama-sama terhadap prestasi belajar yang terjadi pada siswa kelas V SDN Tambaksari 1 Surabaya. Telah terbukti variabel (X1) status sosial ekonomi dan (X2) motivasi belajar secara bersama-sama terhadap (Y) prestasi belajar R hitung $>\mathrm{R}$ tabel $(0,543>0,254)$. Jadi pada penelitian siswa kelas V SDN Tambaksari I Surabaya. (1) terdapat pengaruh positif variabel (X1) status sosial ekonomi dengan variabel (Y) prestasi belajar. (2) Terdapat pengaruh positif variabel (X2) motivasi belajar dengan variabel (Y) prestasi belajar. (3) Terdapat pengaruh positif variabel (X1) status sosial ekonomi dan variabel (X2) motivasi belajar secara bersama-sama terhadap variabel (Y) prestasi belajar.

\section{SIMPULAN}

Berdasarkan hasil pembahasan analisis data melalui pembuktian terhadap hipotesis dari Belajar Terhadap Prestasi Belajar Siswa Kelas V SDN Tambaksari I Surabaya yang telah dijelaskan pada BAB IV, maka dapat disimpulkan sebagai berikut: (1) Terdapat pengaruh positif dan signifikan antara Status Sosial Ekonomi dengan Prestasi Belajar Siswa yang ditunjukan dengan $\mathrm{R}$ hitung $>\mathrm{R}$ tabel $(0,379>0,254)$ (2) Terdapat pengaruh positif dan signifikan antara Motivasi Belajar dengan Prestasi Belajar Siswa yang ditunjukan dengan $\mathrm{R}$ hitung $>\mathrm{R}$ tabel $(0,453>0,254)$. (3) Terdapat pengaruh positif dan signifikan antara Status Sosial Ekonomi dan motivasi Belajar secara bersama-sama terhadap Prestasi Belajar Siswa Surabaya yang ditunjukan dengan
R hitung $>\mathrm{R}$ tabel $(0,543>0,254)$.

\section{REFERENSI}

[1] Dewantara, K. H. (2016, Maret Rabu). Konsep Pendidikan. Retrieved from Media Online: http://wordpress.com

[2] 2003, U. N. (2016, Maret Rabu). Definisi Pendidikan. Retrieved from Media Online: http://akhmaadsudrajat.wordpress.com

[3] Sumardi, S. (2011). Analis Regresi. Jakarta: Grafindo Perkasa Rajawali.

[4] Friedman. (2004). Keperawatan Keluarga. Jakarta: EGC.

[5] Anni, C. T. (2006). Psikologi Belajar. Semarang: Unnes.

[6] Sardiman. (2011). Interaksi dan Motivasi Belajar Mengajar. Jakarta: Rineka Cipta.

[7] Sugiyono. (2007). Statiska Untuk Penelitian. Bandung: Alfabeta. 